\title{
OBITUARIO \\ OLAFF OLMOS FIGUEROA (1951-2005)
}

Un camino de consecuencia: Olaff Olmos Figueroa, arqueólogo tarapaqueño (1951-2005), testimonio de Julio A. Sanhueza ${ }^{1}$

No estaba el hombre, estaba el trabajador y su casa era de piedra, de piedra que sangra, porque nunca se terminaba de hacer...

(Efraín Barquero, de "El trabajador")

Ha partido un hombre consecuente, un profesional comprometido con la justicia y los derechos humanos, con el desarrollo de la sociedad y de su país, con la vida. El 15 de julio del año 2005 falleció en la nortina ciudad de Arica el destacado arqueólogo, y amigo de muchos, Olaff Gregorio Olmos Figueroa, hecho que ocurre cuando participa en actividades relacionadas con el surgimiento de la Región de Tarapacá, su región de origen y con la cual estaba profundamente arraigado. Olaff deja así una existencia centrada en la intervención social, en el esfuerzo por hacer aportes a su territorio y a su gente, tarea que ya había emprendido desde muy joven, cuando siendo estudiante de enseñanza media tomó conciencia de las injusticias sociales y se identificó con los más desposeídos.

Estas palabras, redactadas a su memoria, se centran más bien en sus aportes para el ámbito antropológico, sin que dejemos de reconocer lo valioso de su tarea y obras en otras áreas en que se desempeñó.

Olaff nació el 19 de noviembre de 1951 en la oficina salitrera Peña Chica, en pleno Desierto de Atacama. Estudió en el Liceo de Hombres de la ciudad de Iquique. El año 1972 ingresa a la Escuela de Arqueología de la Universidad del Norte, en Antofagasta, donde empieza a destacarse por el nivel que demuestra en el estudio de la disciplina. El golpe militar lo impacta como a todos, pero él decide continuar sus estudios, sin perder su consecuencia ideológica y sus compromisos sociales y políticos.

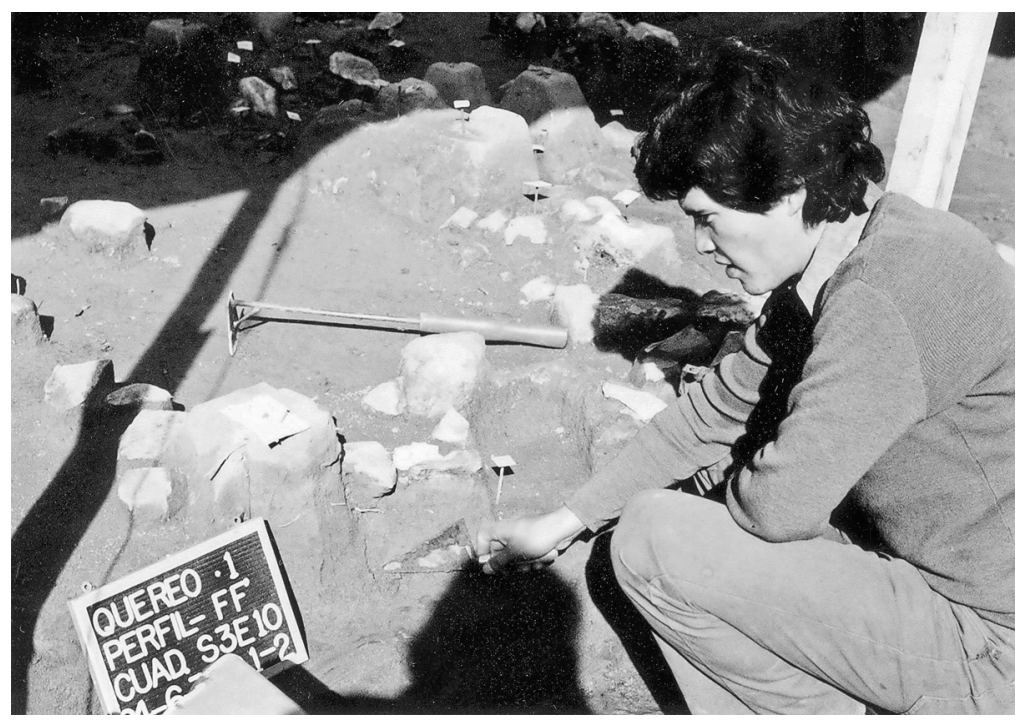

El arqueólogo Olaff Olmos a los 26 años de edad, miembro del equipo interdisciplinario en el sitio paleoindio de Quereo-Los Vilos, 1977 (Fotografía gentileza de Lautaro Núñez).

1 Sociedad Chilena de Arqueología, julioarmand42@gmail.com 
En tanto estudiante destacado, en la Universidad Olaff era conocido por su fuerte temperamento, su seriedad y el profundo compromiso con el que se dedicaba a sus labores académicas, lo que no le impedía ser solidario y afectivo con quienes éramos sus compañeros y amigos. Profesores lo integraron como alumno ayudante en la docencia y, aventajado en su rendimiento académico, se suma a distintas temporadas de trabajos de campo en diversas zonas arqueológicas, participando en excavaciones tanto en la zona atacameña interior como también en la costa.

Durante el año 1976, el novel arqueólogo participa en la escuela de campo que se organiza a través de un convenio interinstitucional y de apoyo académico entre la Universidad del Norte de Antofagasta y la Universidad de Cornell de Ithaca, New York, dirigida por Thomas F. Lynch y Agustín Llagostera M., y se desarrolla en Chile con extensas temporadas de terreno arduas, enriquecedoras e inolvidables para quienes participamos en ellas: excavaciones en el asentamiento incaico de Catarpe de San Pedro de Atacama y en sitios de Abtao en la costa antofagastina. Por ese mismo tiempo pasa a ser investigador del Centro Isluga de Investigaciones Andinas de la Universidad del Norte, Sede Iquique, sumándose al equipo que dirigían los destacados investigadores Gabriel Martínez y Verónica Cereceda, iniciando las primeras prospecciones arqueológicas en el altiplano tarapaqueño y desarrollando un alto interés por la cultura aymara. Esto lo lleva a permanecer largas temporadas recorriendo el altiplano y sensibilizándose por la situación de vida de las comunidades de pastores, con las que participa en ceremonias, rituales y distintas actividades de la vida diaria.

Durante esos años, también, acude al llamado del Museo Regional de Iquique de la sede universitaria referida, para ser docente en los cursos y talleres que formaban monitores de museo, a lo cual se aplica entusiasta, consecuente con una preocupación por difundir y proteger el patrimonio cultural. Esta misma preocupación le hará asumir, años más tarde, el cargo de Visitador Provincial del Consejo de Monumentos Nacionales.

En julio de 1977 un episodio que va a marcar su vida es cuando las fuerzas represivas del régimen militar lo detienen en la ciudad de Antofagasta, debido a su compromiso ideológico, para luego trasladarlo a Iquique, donde es sometido a múltiples torturas en dependencias secretas. Después de liberarlo, es objeto de constantes seguimientos. Pero su entereza lo hace seguir adelante y en ese mismo año participa como arqueólogo asistente en las investigaciones que sobre el Paleoindio y Arcaico dirige Lautaro Núñez A., financiadas por la Smithsonian Institution de Washington D.C. y en convenio con instancias académicas chilenas; labora en temporadas de campo de los sitios Tiliviche-1b y Cáñamo en Tarapacá y Quereo-1, en Los Vilos. Es también este año en que se convierte en investigador del Museo Arqueológico Gustavo Le Paige de San Pedro de Atacama de la Universidad del Norte, llegando a ser su director en 1980.También junto a Lautaro Núñez, quien fuera su profesor, hace una serie de excavaciones en sitios tempranos tales como el alero rocoso Tilomonte-1, La Cueva de San Lorenzo 1, y prospecciones en el área Talabre-Toconao. A estos suman trabajos de campo en diversos sitios de la zona de San Pedro entre ellos Coyo Pueblo, Solor Pueblo, Pukara de Zapar, Vilama y otros. Además realiza estudios desde la perspectiva antropológica sobre los recursos agropecuarios de la zona. Todo ello le permitirá tener una amplia visión de la cultura atacameña.

Su memoria de título "Análisis cuantitativo y comparativo de dos tests estratigráficos de los campamentos Puripica-1 y Tulán-52, San Pedro de Atacama, Chile", la concluye el año 1980, incursionando en los estudios arqueozoofaunísticos que hasta ese entonces tenían sólo un desarrollo incipiente en la región.

Pero la represión de la dictadura nunca lo había perdido de vista y en la medianoche de un día de marzo del mismo año 1980 es obligado a renunciar "voluntariamente" a su cargo en el Museo en San Pedro de Atacama, bajo amenaza de muerte a él y su familia, por agentes armados. Es así como cerradas las puertas laborales para él y su esposa, deciden partir a la nación ecuatoriana en 1981 e integrarse al Programa Antropología para el Ecuador, siendo Director de una Estación de Campo en la Provincia de Manabí, Área Jipijapa-Ayampe. Allí con su espíritu innovador y la inquietud de ampliar sus horizontes, ejecuta prospecciones arqueológicas en la región litoral central y estudia el sitio OMJPSL 141 que presenta una secuencia del período Formativo Temprano; además participa en la Conferencia Internacional sobre Rescate Arqueológico del Nuevo Mundo auspiciada por la Organización de Estados Americanos, Fondo Nacional para Preservación Histórica de Estados y Gobierno de Ecuador, entre otras actividades. 
Entre los años 1982-1984 estudia en el Programa de Magíster en Antropología Social en la Pontificia Universidad Católica del Perú, Lima, y propicia esta oportunidad para ampliar su formación en temáticas sociales y económicas andinas, participando en encuentros y jornadas académicas de otros centros de estudios tales como la Universidad de San Marcos y el Museo Nacional de Antropología del Perú, además de realizar algunos trabajos de la especialidad.

En el transcurrir desde 1981-1985 su producción científica se expresa en varias publicaciones de arqueología sobre su estudio de fauna prehispánica en la zona atacameña y otras en coautoría sobre el período Precerámico en la costa desértica tarapaqueña y de un cementerio de cistas altiplánico de rango tardío. Retornado a Chile, en 1984, su integración a diversas ONGs regionales le significó su reencuentro con las tierras altas andinas y realizar estudios sobre las comunidades andinas, labor que desempeña hasta 1991. Es esa época en que una serie de proyectos que lleva a cabo se orientarán al desarrollo y mejoramiento de los niveles de vida de las comunidades aymaras del altiplano de Isluga y Cariquima y Valle de Camiña, entre las que se cuentan Chijo, Colchane, Chapi Qoyu, Qota Saya, Mawke y otras, donde promueve programas de educación con currículo culturalmente pertinente, optimización de tecnologías tradicionales, organización y economía campesina.

Uno de los hitos en el trabajo arqueológico de Olaff lo marcan las excavaciones que en 1990 realizó para ubicar los cuerpos de víctimas de la dictadura militar, ejecutados políticos que habían sido inhumados ilegalmente en la localidad costera de Pisagua, en la Región de Tarapacá, donde funcionó un campo de concentración de prisioneros. Así, en una actitud consecuente con sus principios y colaborando con la Comisión Chilena de Derechos Humanos y la Vicaría de la Solidaridad, continúa con la búsqueda de los cuerpos de ejecutados por el régimen militar en las fosas del Patio 29 en el Cementerio General de Santiago. Luego sigue en estos trabajos en las localidades de Paine, La Rana, Pintúe en la Región Metropolitana y posteriormente lo hace en Copiapó, contribuyendo de esta manera a la justicia y en cierta medida a mitigar la incertidumbre y dolor de los familiares de los desaparecidos al hallar sus restos.

A partir de 1991 asume como Director Regional de Turismo de la Región de Tarapacá, donde además de las labores ejecutivas relativas a su cargo no deja de lado su relación con las comunidades campesinas e indígenas de la región y su interés por la preservación y difusión del patrimonio cultural regional.

A la Corporación Nacional de Desarrollo Indígena, Subdirección Nacional Norte, pasa a formar parte el año 1997, desempeñándose como encargado en distintas unidades vinculadas al desarrollo territorial, a estudios y planificación y especialmente del área de Desarrollo Indígena Aymara Jiwasa Oraje. En esta repartición continúa en la línea de trabajo por el progreso y mejoramiento económico y social de las comunidades originarias.

Desde el año 2002 se encontraba desempeñando el cargo de Secretario Regional Ministerial de Minería para la Región de Tarapacá, gestión en la cual se destacó.

Entre sus recientes intervenciones, no puede dejarse de destacar aquí su compromiso, preocupación y gestión en los problemas de las comunidades andinas rurales del interior de Iquique y Pisagua, suscitados por el último terremoto que afectó a la región.

Retomando la obra docente, después de desempeñarse como formador de monitores de museo y en talleres y jornadas sobre la cultura aymara cuando era parte de los centros de estudios regionales, su labor de maestro se reinicia en la Carrera de Técnico en Turismo de la Universidad Arturo Prat de Iquique donde es Académico en 1995 y con posterioridad continúa en el 2004 en la Carrera de Antropología y Arqueología de la Universidad Bolivariana (Sede Iquique). Allí aprovecha de entregar parte de su gran experiencia a los estudiantes, quienes le consideraban no sólo un gran profesor, sino también una excelente persona. Con ellos alcanzó a compartir jornadas ricas en conocimientos y en anécdotas de su multifacética vida que aportaban ejemplos de cómo asumir la profesión arqueológica.

En el lapso de su vida, Olaff asistió a numerosos congresos, seminarios, eventos y reuniones científicas, haciendo aportes desde el plano de la arqueología, la antropología y las ciencias sociales, evidentemente a esto se suma su participación en los múltiples eventos ligados al desarrollo regional a los que concurrió como funcionario ejecutivo y autoridad.

Llevó a cabo numerosas publicaciones, y entre toda su producción intelectual y técnica hemos querido rescatar aquí la que se inserta como aporte a las disciplinas antropológicas o se vincula a ellas por su 
enfoque; trabajos que, en un amplio espectro, dan muestra de sus capacidades y versatilidad académica y profesional. Estos cubren desde estudios de arqueología prehistórica, donde se encuentran trabajos que ya mencionábamos, hasta documentos de orientación etnográfica y otros con sustento en la antropología social andina. Existen, además, obras que dejó en manuscritos, una vinculada a su experiencia como arqueólogo forense en casos de violación a los derechos humanos por la dictadura militar chilena y otra sobre la cultura aymara tarapaqueña; ambas pretenden publicarlas sus hijos, que siguen su huella en la antropología (ver bibliografía).

Para concluir este sencillo homenaje, reiteramos que solo está un segmento de todo lo realizado por este arqueólogo y profesional de las ciencias sociales. No nos referimos a sus otros estudios de postgrado, ni a sus aportes realizados en el plano del desarrollo social y económico para la Región de Tarapacá o como Secretario Regional de Minería. Quisimos solo reseñar su paso por el mundo de la ciencia antropológica.

Con la partida de Olaff Olmos se fue un luchador, un arqueólogo destacado que dejó la indeleble huella de su obra, la que no se centró sólo en la producción científica de su disciplina. Sus conocimientos y capacidades estuvieron al servicio del crecimiento de su región, de su país y también fueron una herramienta de lucha por los derechos humanos y contra la injusticia.

Agradecimientos: Agradezco el apoyo de mi amiga Emma Torres López, compañera de Olaff por largos años; de sus hijos, especialmente Sebastián Olmos Torres, que hizo posible estas notas; también a Viviana Ramírez de la Escuela de Arqueología, Universidad Bolivariana de Iquique, y a Daymond Flores del IECTA, Iquique, por sus gentiles colaboraciones. Finalmente mi reconocimiento a los editores de Chungara, Revista de Antropología Chilena, por la oportunidad de hacer esta memoria de quien fuera un gran compañero y amigo.

Santiago, 2005.

\section{Bibliografía}

1980 Análisis cuantitativo y comparativo de dos tests estratigráficos de los campamentos Puripica-1 y Tulán-52, San Pedro de Atacama, Chile. Memoria de Título. Departamento de Arqueología, Universidad del Norte, Antofagasta.

1981 Usamaya 1, cementerio indígena en Isluga, Altiplano de Iquique I Región. Chile, en coautoría con Julio Sanhueza T. Chungara 8:169-208.

1981 Informe preliminar. Programa de Arqueología del Área SW. Provincia de Manabí. Documentos Internos. Programa de Antropología para el Ecuador.

1983 Subsistencia y utilización de estudios faunísticos en economías de caza-recolección de la puna de Atacama, Norte de Chile. Revista Antropológica 1:99-120. Pontificia Universidad Católica del Perú, Lima.

1984 El precerámico en la Costa-Sur de Iquique, en coautoría con Julio Sanhueza T. Chungara 13:143-154.

1985 Análisis de fauna arqueológica: Un indicador cultural de adaptación humana en el desierto. Chungara 14:45-48.

1986 Muspa Uywani - Muspa Llapuni. Documentos de Trabajo. Taller de Estudios Regionales, Iquique.

1987 El boletín de difusión aymara: comunicación social alternativa. Actas del I Congreso de Antropología Chilena, Santiago.

1988 Algunas notas sobre historia de los aymara. Documentos de Trabajo 1. Taller de Estudios Regionales, Iquique.

1988 Derechos indígenas y nuevo escenario: legislación chilena y Pueblos indígenas. Apuntes para el caso aymara. Documentos de Trabajo 5. Taller de Estudios Regionales, Iquique.
1988 La Arqueología como disciplina científico social. Documentos de Trabajo 11. Taller de Estudios Regionales, Iquique.

1988 La explotación del guano y esclavos chinos en las covaderas. Revista Camanchaca 6:12-16. Taller de Estudios Regionales, Iquique.

1988 Derechos Humanos y Pueblos Indígenas. Territorialidad y Legislación en los Aymaras del Norte de Chile, en coautoría con Eduardo Pérez R. Taller de Estudios Regionales, Iquique.

2001 Etnoturismo en Mamiña: El circuito de la Cultura de Kepiskala. En Experiencias y Perspectivas en el Desarrollo Territorial de los Pueblos Indígenas de Chile. Corporación Nacional de Desarrollo Indígena, Ministerio de Planificación.

2005 Urco-Uma: Percepción del espacio, manejo de recursos y tecnología agraria en Isluga. Norte de Chile. Revista de la Secretaría Regional de Gobierno. I Región de Tarapacá (en prensa).

2005 Tiempo cíclico: Tiempo de siembra, tiempo de cosecha entre los aymara de Tarapacá, Norte de Chile. Revista de Ciencias Sociales. Universidad Arturo Prat, Iquique (en prensa).

2005 Patrimonio cultural, etnoturismo y desarrollo indígena. Revista de Ciencias Sociales. Universidad Arturo Prat, Iquique (en prensa).

2006 Arqueología del Crimen: Evidencias de una Historia Reciente. Manuscrito en preparación para su publicación.

2006 Etnografía a Color. Manuscrito en preparación para su publicación. 